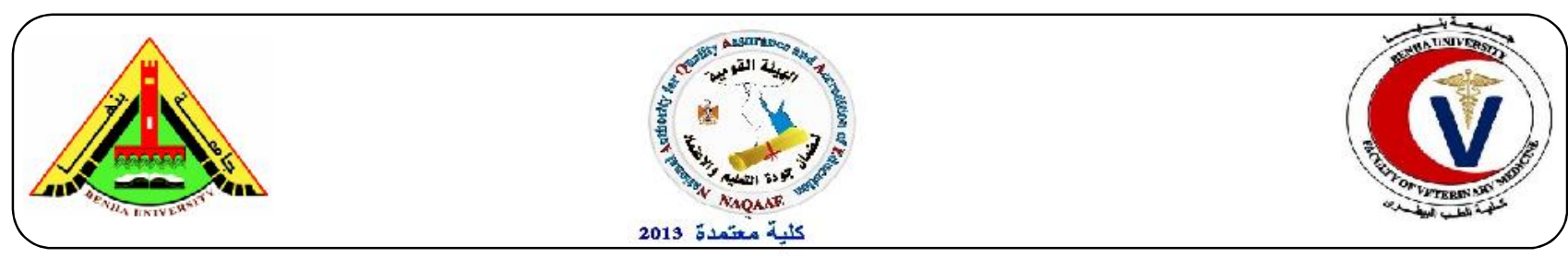

\title{
Impact of Chitosan and Calcium phosphate nanoparticles upon VERO cells and their adapted PPRV
}

\author{
Gabr. F. El-Bagoury ${ }^{1}$, Ehab. M. EL-Nahas ${ }^{1}$, Ahmed Husien Mostafa ${ }^{2}$, Mohamed abd el bar saafan ${ }^{2}$ \\ ${ }^{1}$ Department of virology, Faculty of Veterinary Medicine, Benha University \\ ${ }^{2}$ Veterinary serum and vaccine Research institute, Abbasia, cairo.
}

\section{A B S T R A C T}

Nanotechnology that created nanoparticles (NP) having superior properties compared to the original ones offers a vast era for PPR vaccine improvement. African green monkey kidney VERO cell lines were widely used for isolation and propagation of Peste des petits ruminants virus (PPRV) instead of primary cell lines because of the problematic quality and considerable variations in primary cultures. In this study, investigations for the impact of Chitosan nanoparticles (CSN) and Calcium phosphate nanoparticles $(\mathrm{CaPN})$ upon the principle biological elements, VERO cells (in terms of cytotoxicity) and PPRV performance (in terms of cytopathic effect $\{\mathrm{CPE}\}$ and virus titer) were carried out using primary concentrations of both nanoparticles as $1 \%(\mathrm{w} / \mathrm{v}), 5 \%(\mathrm{w} / \mathrm{v}), 10 \%(\mathrm{w} / \mathrm{v})$ then, further concentrations of $0.5 \%(\mathrm{w} / \mathrm{v}), 0.25 \%(\mathrm{w} / \mathrm{v})$ and $0.125 \%(\mathrm{w} / \mathrm{v})$ were also used. These concentrations were used as supplements to the minimum essential media (MEM) that were regularly used in PPR vaccine production. The results of the study revealed that along of a successive four days of microscopically examined VERO cells that were overlaid with either MEM only or MEM supplemented with different concentrations of $\mathrm{CSN}$ and $\mathrm{CaPN}$, the lowest concentrations of $0.125 \%(\mathrm{w} / \mathrm{v})$ for CSN and CaPN were the minimally cytotoxic for VERO cells in terms of the ratio among the number of microscopic fields of affected cells comparing to the overall cultured cells sheet, However, the higher the concentration of CSN/CaPN, the higher the VERO cells cytotoxicity. Also, the impact of CSN/CaPN different concentrations supplied MEM upon PPRV performance after inoculating VERO cells revealed that, along seven days of microscopically examined and PPRV inoculated VERO cells that were overlaid with aforementioned concentrations from both of CSN and CaPN did not show any significant impact regarding CPE onset and intensity of eruption or as a PPRV titer (expressed by $\log 10 \mathrm{TCID} \mathrm{C}_{50} / \mathrm{ml}$ ) and may need further investigations. So, the obtained results from this study recommend the concentration to be used as a MEM supplement during the process of preparing a CSN/CaPN based PPR vaccine was $0.125 \%(w / v)$ or less for keeping a considerable VERO cells viability.

Keywords: PPRV, VERO cells, Chitosan nanoparticles and Calcium phosphate nanoparticles.

(http://www.bvmj.bu.edu.eg) (BVMJ-35(2): 597-611, 2018)

\section{INTRODUCTION}

Pestes des petits ruminants (PPR) is an acute viral disease of small ruminants characterized by high fever, nasal discharges, stomatitis, diarrhea and pneumonia (OIE, 
2004). The disease is caused by PPR virus that belongs to genus morbillivirus and family paramyxoviridae (Gibbs et al.,1979). It was firstly appeared in Egypt in 1987(Ikram et al.1988). Vaccination considered as the most cost-effective biomedical way to control infectious disease in livestock using either live attenuated or inactivated vaccines (Paillot et al.,2008).

Nanotechnology offers the opportunity to create nanoparticles (NP) varying in composition, size, shape and surface properties, for application in the field of medicine (Moghimi et al., 2005 and Couvreur and Vauthier, 2006). Nanoparticles because of their size similarity to cellular components, can enter living cells using the cellular endocytosis mechanism, in particular pinocytosis (Treuel and Nienhaus, 2013).

Natural polymers based on polysaccharide have also been used to prepare nanoparticles as chitosan, chitosan based nanoparticles have been widely studied due to their biocompatability, biodegradability, nontoxic nature and their ability to be easily modified to different shapes and sizes (Arca et al.,2001, Akagi et al., 2012 and Chua et al., 2012).Also, because of low production costs, biocompatibility and very low toxicity, chitosan is a very interesting excipient for vaccine delivery research (Van Der Lubben et al., 2001). An ionic gelation process based on the positively charged amino groups in chitosan and the negative charge of tripolyphosphate has also been used to prepare chitosan NP in the size range of 20-400 nm (Fernandez-Urrusuno et al., 1999, Xu and Du, 2003).

Easy surface modification of polymeric Nanoparticles has made them very much capable of invention. On another hand, Inorganic Nanoparticles has gained a deep attention as drug delivery agent due to their hydrophilic nature, better stability, easy synthesis, and much higher biocompatibility
(Arteam and Richa (2017).Nowadays, the scientists are focusing on $\mathrm{CaPN}$, because of their better stability and biocompatibility with the biological tissue. Moreover, CaPN are emerging as a second-generation vector for efficient delivery and stabilization of nucleic acids inside cells (Cheng and Kuhn, 2007 and Chen et al. 2014). Calcium phosphate as an inorganic nanoparticles can be produced by mixing calcium chloride, dibasic sodium phosphate and sodium citrate under specific conditions (He et al., 2000 and $\mathrm{He}$ et al., 2002). They are non-toxic and can be formed into a size of 50-100 nm (Joyappa et al., 2009). Theses nanoparticles are useful adjuvants for DNA and mucosal immunity (He et al., 2000, Joyappa et al., 2009 and Mody et al., 2013), and show excellent biocompatibility. Calcium phosphate nanoparticles have largely been examined for use as a delivery system (Oyewumi et al., 2010) and have thus been engineered to promote antigen attachment. Attachment of antigen has been achieved through simple physical adsorption.

\section{Aim of the work}

The aim of current work is to investigate the impact of CSN and CaPN upon VERO cells expressed in terms of cytotoxicity (morphological changes to cells) and PPRV performance expressed in terms of cytopathic effect $\{\mathrm{CPE}\}$ and virus titer as the essential biological elements that were used in PPR vaccine preparation. Experiments were carried out using primary concentrations of both nanoparticles as $1 \%(\mathrm{w} / \mathrm{v})\{30 \mu \mathrm{g} / \mathrm{ml}\}, 5 \%(\mathrm{w} / \mathrm{v})$ $\{150 \mu \mathrm{g} / \mathrm{ml}\}, 10 \%(\mathrm{w} / \mathrm{v}) \quad\{300 \mu \mathrm{g} / \mathrm{ml}\}$ then, further concentrations of $0.5 \%(\mathrm{w} / \mathrm{v})\{15 \mu \mathrm{g} / \mathrm{ml}\}, 0.25 \%(\mathrm{w} / \mathrm{v})\{7.5 \mu \mathrm{g} / \mathrm{ml}\}$ and $0.125 \%(\mathrm{w} / \mathrm{v})\{3.75 \mu \mathrm{g} / \mathrm{ml}\}$ were also used. These concentrations were used as supplements to the minimum essential media (MEM) that were regularly used in PPR vaccine production. 


\section{Materials and Methods}

\subsection{Virus:}

The Nig/75 strain of PPRV (with a titer of $10^{6}$ TCID 50/ml) was provided from Rinderpest virus research department, veterinary serum and vaccine research institute, Cairo. Used for virus titration.

\subsection{VERO cells (Green monkey kidney} cells):

It was maintained and grown in Eagles minimum essential media supplemented with $10 \%$ newly born calf serum, antifungal, penicillin sodium $100 \mathrm{IU} / \mathrm{ml}$ and streptomycin $100 \mathrm{mg} / \mathrm{ml}$. It was used in cytotoxicity and virus titration. Obtained from VACCERA, Giza, Egypt.

\subsection{Chitosan nanoparticles preparation:}

Chitosan is a linear polysaccharide composed of randomly distributed -(1-4) linked Dglucosamine (deacetylated unit) and N-acetylD-glucosamine. It was extracted from marine shrimp shells with a degree of deacetylation of $85 \%$ and molecular weight of $220 \mathrm{kDa}$ as determined by Qurashi et al. (1992). Chitosan nanoparticles preparations were performed by dissolved chitosan at $5 \%(\mathrm{w} / \mathrm{v})$ with $1 \%(\mathrm{w} / \mathrm{v})$ acetic acid (HOAc) then $\mathrm{pH}$ adjusted to $4.6-$ 4.8 with $10 \mathrm{~N} \mathrm{NaOH}$. CSN were formed by the principle of ionic crosslinking between positively charged chitosan and negatively charged sodium tripolyphosphate (TPP) $(0.25 \% \mathrm{w} / \mathrm{v})$ according to Zhao et al., (2012). Chitosan nanoparticles were formed by dropping TPP to the chitosan solution with the ratio of (1:5) with magnetic stirring at room temperature for overnight. CSN was separated by centrifugation at $10,000 \mathrm{rpm}$ for 30 minutes at $4{ }^{\circ} \mathrm{C}$ and the supernatant was discarded while the sediment was reconstituted to the original volume with PBS, So, a stock CSN suspension with a concentration of $3 \mathrm{mg} / \mathrm{ml}$ was obtained. CSN suspension was added to MEM with ratios of $10 \%(300 \mathrm{ug} / \mathrm{ml}), 5 \%(150 \mathrm{ug} / \mathrm{ml})$ and $1 \%$ (30ug/ml) Qi et al., (2004). Chitosan was obtained from Naquaa foundation, Giza, Egypt.

\subsection{Calcium Phosphate nanoparticles preparation:}

Calcium phosphate $(\mathrm{CaPN})$ is amorphous nano-powder, $<150 \mathrm{~nm}$ particle size. It was obtained from Sigma Aldrich and prepared by dissolving in deionized water to make $10 \%$ stock and the solution subjected to continuous stirring for 6 hours at room temperature, followed by sonication for three times repeated cycles each of 15 minutes, according to Saeed et al., (2015).

\subsection{Measuring of nanoparticles size with} Transmission electron microscopy (TEM): Samples of nanoparticles were prepared for transmission electron microscopy according to Temchura et al., (2014), by dispersing in ultrapure $\mathrm{H} 2 \mathrm{O}$ at about $10 \%$ concentration and ultrasonicated at $1000 \mathrm{~L}$ for 15 minutes. One drop of this liquid was immediately transferred by a micropipette to a $3 \mathrm{~mm}$ diameter Form var coated copper TEM grid and slowly evaporated to dryness. The samples on the TEM grid were analyzed using a 100cx JEOL $\mathrm{TEM}$ at $80 \mathrm{kV}$ at Naquaa foundation, Giza, Egypt.

\subsection{Cytotoxicity of Chitosan and Calcium} Phosphate nanoparticles on VERO cells:

For each Nanoparticle (CSN/CaPN), twelve cell culture flasks of $75 \mathrm{ml}$ volume are distributed into four groups and in which VERO cells were subcultured, then after 48 hours, replacement with the existing media (MEM) took place using different concentrations (primary concentrations) of the nanoparticles $1 \%, 5 \%$ and $10 \%$ for the first three groups while the remaining group of flasks were subjected to media change only with blank MEM to be used as a cell control. All these groups were daily observed for any morphological changes in cells as cell rounding, detachment from the surface or any other changes that indicates any signs of cytotoxicity. By progress of work there was a 
need for constructing additional 15 flasks in 5 groups, where the first 4 groups were devoted for further concentrations ((secondary concentrations) as $1 \%, 0.5 \%, 0.25 \%$ and $0.125 \%$ while the fifth group was kept as a cell control group.

\subsection{Measuring of VERO cells viability during cytotoxicity tests:}

The microscopic examination and daily observations against morphological changes that may happen among cultured VERO cells, were still used as an indicator for cytotoxicity assessments (Fischer et al., 2003 and Janvikul et al., 2007). Only one observer who recorded the results all experiments for accuracy and standardization.

Measures were converted to percentages on the bases of the ratio between the number of affected microscopic fields to the overall cell culture sheet.

2.8. Sequential detection of PPRV cytopathogenicity on VERO cells in presence of different concentrations of nanoparticles:

Tissue culture flasks ( $75 \mathrm{ml}$ prescriptions) with complete monolayer of VERO cells were used for inoculation with the PPRV. Freeze dried virus seed was reconstituted in $10 \mathrm{ml}$ of cell culture medium without serum, medium was discarded from the flasks prior to inoculation with PPR virus $\left(10^{-5}\right.$ TCID50/ml). After even distribution of virus onto the cells, the flasks were incubated at $37^{\circ} \mathrm{C}$ for 30 minutes in order to allow viral attachment. $30 \mathrm{ml}$ of fresh tissue culture growth medium enriched with 5\% serum was then added to each of the flasks and incubated at $37^{\circ} \mathrm{C}$. The same process were done using different concentrations of $\mathrm{CSN} / \mathrm{CaPN}$ instead of the tissue culture growth media. VERO cells infected with PPR virus were regularly examined to detect any cytopathogenic effect (CPE). Growth medium was also regularly examined and replaced by fresh growth medium as and when required. Cells were incubated until 70-80\% CPE was observed. (Abbas et al., 2011). VERO cells grown in standard conditions yielded complete monolayer of cells in tissue culture flasks in 72 hours. VERO cells were spindle shaped, appeared as single cells as well as patches of cells which later developed into complete monolayer. The infected VERO cells with PPRV were observed with 70-80\% CPE in 5 days. CPE was characteristic with rounding and aggregation of vero cells on 4th day whereas generalization of CPE was observed on 5th day post infection. Formation of syncytia is reported by Lefevre and Diallo (1990), Mohan (2004) and John et al. (2006)

\subsection{Virus titration:}

The virus titration of the prepared virus fluids was performed using the 10-fold dilution inoculated onto VERO cells microtiter-plate according to OIE (2010) and the virus titer was calculated following the rules given by Reed and Muench (1938).

\subsection{Minimum Essential Medium (MEM):}

It was purchased from Sigma, USA. Minimum Essential Medium (MEM) with Hank's salts and L-glutamine without sodium bicarbonate was used for the growth and maintenance of cell cultures. The growth medium was supplemented with $10 \%$ newborn calf serum, while the maintenance medium was supplemented with $2 \%$ newborn calf serum. The final $\mathrm{pH}$ of the growth and maintenance media were approximately adjusted to 7.2 .

\section{RESULTS}

\subsection{Measuring of nanoparticles size with Transmission electron microscopy (TEM):}

Particles size of the CaP Nanoparticles (CaPN) showed mean particles distribution of $150 \mathrm{~nm}$ while, the particles size of Chitosan Nanoparticles (CSN) showed mean particles distribution of $85 \mathrm{~nm}$ using Transmission Electron microscopy (TEM) with direct mag.30000-120000X. Figure (1). 


\subsection{Cytotoxicty of $\mathrm{CSN}$ and CaPN upon VERO cells at $1 \%, 5 \%$ and $10 \%$ concentrations:}

Referring to table (1) and chart (1), it was observed that CSN 1\% showed the lowest cytotoxicity among other concentrations (5\% \& 10\%). However its safety profile was not satisfactory as by the 4th; day of adding to cells, only $50 \%$ of the cells were not suffering from changes, this is being along with the accelerated declining pattern of cell viability from $90 \%, 80 \% \& 70 \%$ then $50 \%$ in the 1st;,2nd, 3rd \&4th days indicated more and more declining must to be logically anticipated. $10 \%$ concentration showed a dramatic impact upon cells that showed $20 \%$ cell viability by the $1 \mathrm{st}$; day of the experiment and cells suffered latterly from deformities and detachments until reaching the 4th; day with all cells destroyed.

These disappointing results confirmed the need for more investigations regarding cytotoxicity but after doing further dilutions from CSN stock solution.

As shown in table (2) and chart (2), It was noticeable that the effect of CaPN on VERO cells was more or less the same as that of CSN and also the concentration $1 \%$ was safer but unsatisfactory concentration. These findings also pointed to the need for further dilutions for more investigations.

\subsection{Cytotoxicty of $\mathrm{CSN}$ and CaPN upon VERO cells at $1 \%, 0.5 \%, 0.25 \% \& 0.125 \%$ concentrations:}

Referring to table (3) and chart (3), further dilutions were prepared in a double fold pattern as $1 \%, 0.5 \%, 0.25 \%$ \& $0.125 \%$ concentrations for yielding more confirmed and reliable results about tolerability of CSN upon VERO cells used for PPR vaccine manufacturing .It was noticed that the more the dilution degree, the less the cytotoxicity observed. For instance, at the end of the 4th; day of the experiment, the cytotoxicity of both MEM (cell control) and the highest dilution $(0.125 \%)$ were almost offering the same level of safety upon VERO cells.

These results were confirmed afterwards by a further subculture for the cells in all groups where MEM \& $0.125 \%$ concentration groups showed a normal pattern of cell growth, on the contrary other concentrations showed various degrees of cytotoxicity like cell rounding, detachments and other signs.

Respecting to table (4) and chart (4), the same results in case of $\mathrm{CaPN}$ concentrations $(1 \%, 0.5 \%, 0.25 \% \& 0.125 \%)$ could be easily distinguished however, by the end of the 4th; day in $0.5 \%$ as well as $0.25 \%$ concentrations the suffering of cells seemed less than observed in the same concentrations of CSN.

Also, further subculture performed for MEM and $0.125 \%$ concentration groups revealed a normal pattern of cell growth, on the contrary of other concentrations of CaPN.

\subsection{Effect of CSN/CaPN upon PPRV performance after inoculation in VERO cells}

Referring to tables no.(5,6,7 and 8), charts no.(5and 6)\& figures no.(3, 4 and 5), in this work we studied the performance of inoculated PPRV to VERO cells, on a simultaneous exposure to different (CSN/CaPN) concentrations that were supplemented in media. the assessment based qualitatively on follow up and observations for the eruption of cytopathic effect (CPE) of virus upon inoculated VERO cells and graded in terms of pluses while a quantitative assessment -via virus titration- was performed along seven days to confirm the results numerically. It was easily recognizable that the performance of virus was not affected progressively with the existence of nanoparticles in media on concurrently with inoculation of virus. 
All CSN/CaPN concentrations were employed for ensuring that there was a negligible impact of higher $\mathrm{CSN} / \mathrm{CaPN}$ concentrations upon PPRV.

Although the apparent morphology of VERO cells that were either affected with NP cytotoxicity or affected PPRV activity (CPE) appeared closely similar specially cells rounding but on the other hand the onset of
CPE (in normal conditions) usually expected after the third or even the fourth day in a localized and scuttered manner in cell cultured sheet. Afterwards, spreading of CPE will takes place. But in cytotoxicity, the generalized morphological changes and cells detachment all over cell cultured sheet paid the attention towards cytotoxicity rather that $\mathrm{CPE}$ due to PPRV activities.

Table 1. Cytotoxicity of 1ry, concentrations (1\%,5\% and10\%) of CSN on VERO cells in terms of cell viability percentage.

\begin{tabular}{ccccc}
\hline $\begin{array}{c}\text { Media } \\
\text { Type }\end{array}$ & \multicolumn{3}{c}{ Percent of cell viability/day post treatment } \\
\\
& Day 1 & Day 2 & Day 3 & Day 4 \\
\hline MEM & $100 \%$ & $100 \%$ & $100 \%$ & $100 \%$ \\
CSN 1\% & $90 \%$ & $80 \%$ & $70 \%$ & $50 \%$ \\
CSN 5\% & $50 \%$ & $40 \%$ & $25 \%$ & $10 \%$ \\
CSN 10\% & $20 \%$ & $10 \%$ & $5 \%$ & $0 \%$ \\
\hline
\end{tabular}

Chart 1. Cytotoxicity of 1ry, concentrations (1\%,5\%\&10\%) of CSN on VERO cells in terms of cell viability

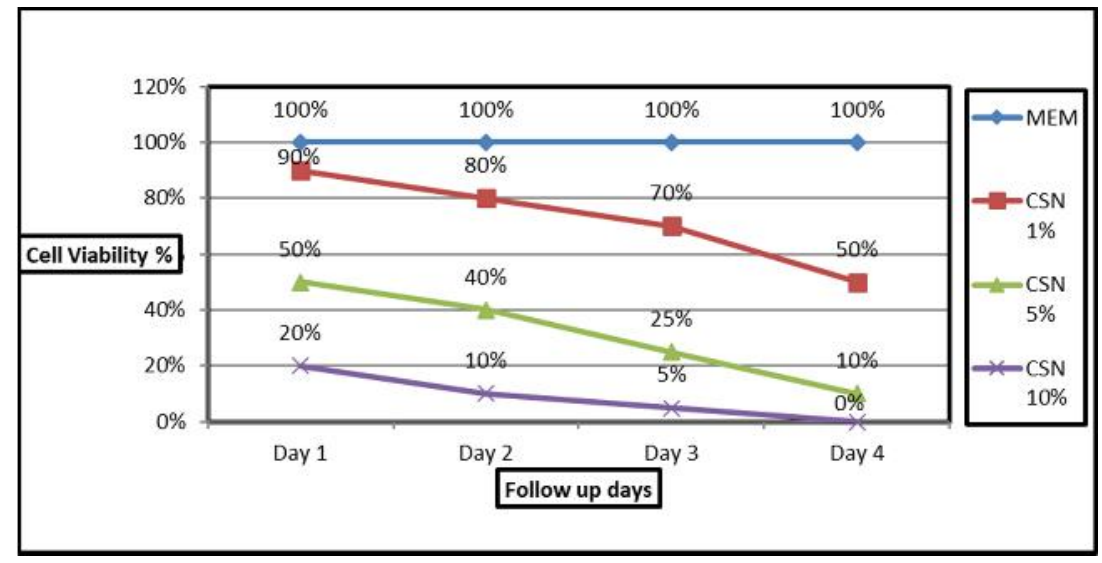

Table 2. Cytotoxicity of 1ry, concentrations (1\%,5\% and10\%) of CaPN on VERO cells in terms of cell viability percent.

\begin{tabular}{lllll}
\hline $\begin{array}{l}\text { Media } \\
\text { Type }\end{array}$ & \multicolumn{4}{l}{ Percent of cell viability/day post treatment } \\
& Day 1 & Day 2 & Day 3 & Day 4 \\
\hline MEM & $100 \%$ & $100 \%$ & $100 \%$ & $100 \%$ \\
CaPN 1\% & $90 \%$ & $80 \%$ & $75 \%$ & $60 \%$ \\
CaPN 5\% & $70 \%$ & $60 \%$ & $50 \%$ & $40 \%$ \\
CaPN 10\% & $40 \%$ & $30 \%$ & $25 \%$ & $20 \%$ \\
\hline
\end{tabular}


Impact of Chitosan and Calcium phosphate nanoparticles upon VERO cells and their adapted PPRV

Chart 2. Cytotoxicity of 1ry, concentrations (1\%,5\% and10\%) of CaPN on VERO cells in terms of cell viability percent

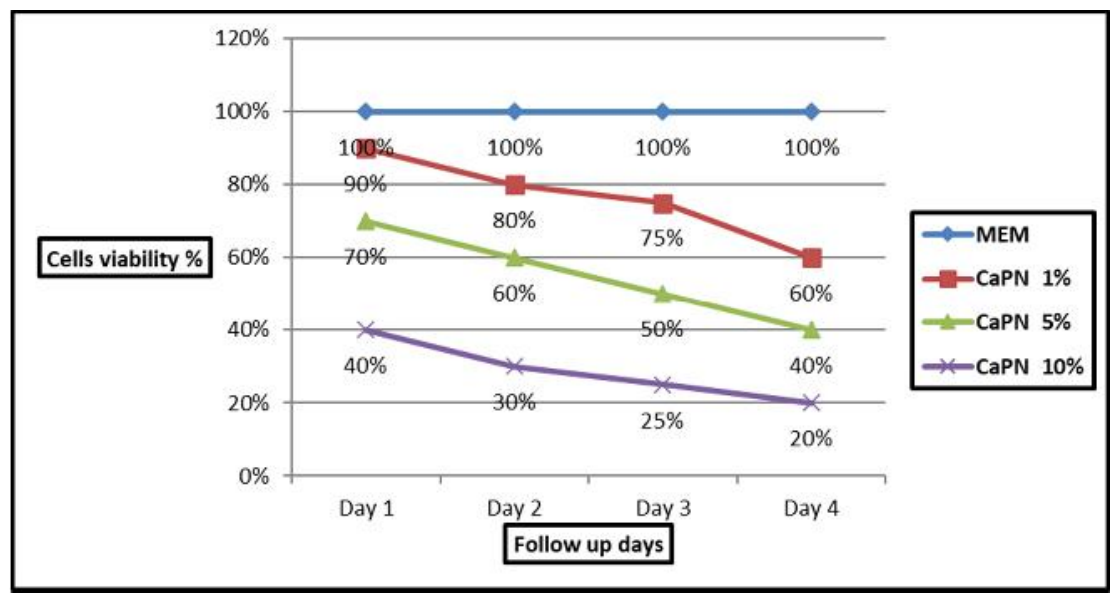

Table 3. Cytotoxicity of 2ry, concentrations $(1 \%, 0.5 \%, 0.25 \%$ \& $0.125 \%)$ of CSN on VERO cells in terms of cell viability percentage.

\begin{tabular}{ccccc}
\hline $\begin{array}{l}\text { Media } \\
\text { Type }\end{array}$ & \multicolumn{3}{c}{ Percent of cell viability/day post treatment } \\
& Day 1 & Day 2 & Day 3 & Day 4 \\
\hline MEM & $100 \%$ & $100 \%$ & $100 \%$ & $100 \%$ \\
CSN 0.125\% & $100 \%$ & $100 \%$ & $95 \%$ & $95 \%$ \\
CSN 0.25\% & $95 \%$ & $85 \%$ & $80 \%$ & $75 \%$ \\
CSN 0.50\% & $95 \%$ & $85 \%$ & $75 \%$ & $60 \%$ \\
CSN 1\% & $90 \%$ & $80 \%$ & $70 \%$ & $50 \%$ \\
\hline
\end{tabular}

Chart 3. Cytotoxicity of 2ry, concentrations $(1 \%, 0.5 \%$ and $0.25 \%$ \& $0.125 \%)$ of CSN on VERO cells in terms of cell viability percentage.

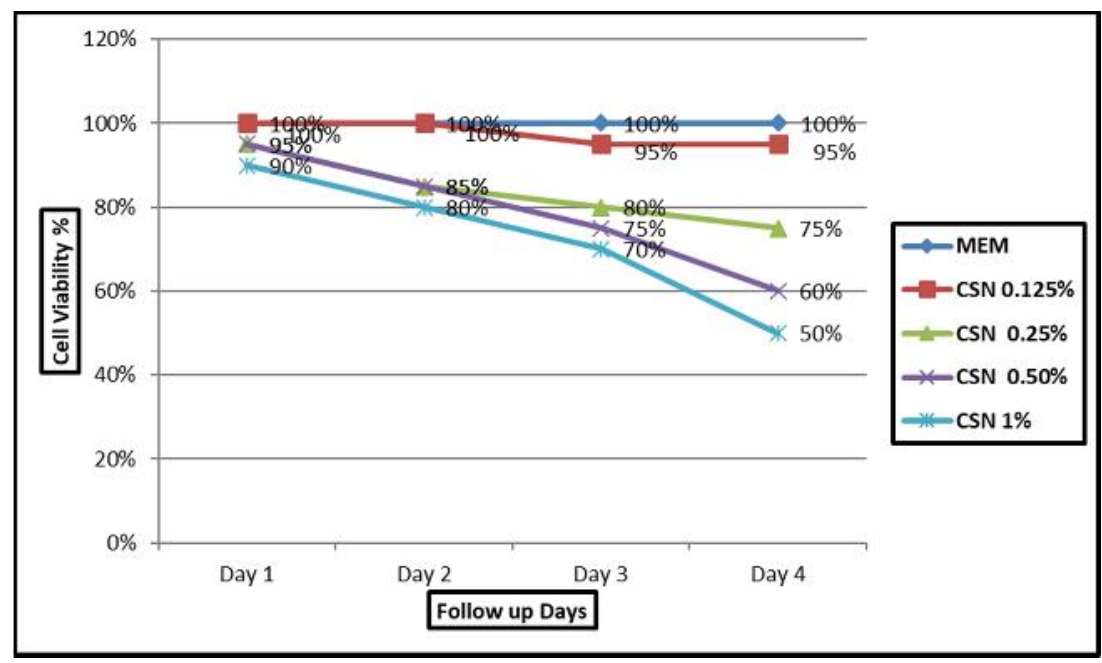


El-Bagoury et al. (2018). BVMJ-35(2) : 597-611

Table 4. Cytotoxicity of 2ry, concentrations $(1 \%, 0.5 \%, 0.25 \%$ and $0.125 \%)$ of CaPN on VERO cells in terms of cell viability percentage.

\begin{tabular}{ccccc}
\hline $\begin{array}{c}\text { Media } \\
\text { Type }\end{array}$ & \multicolumn{3}{c}{ Percent of cell viability/day post treatment } \\
& Day 1 & Day 2 & Day 3 & Day 4 \\
\hline MEM & $100 \%$ & $100 \%$ & $100 \%$ & $100 \%$ \\
CaPN 0.125\% & $100 \%$ & $100 \%$ & $95 \%$ & $95 \%$ \\
CaPN 0.25\% & $95 \%$ & $90 \%$ & $85 \%$ & $75 \%$ \\
CaPN 0.50\% & $90 \%$ & $85 \%$ & $80 \%$ & $75 \%$ \\
CaPN 1\% & $90 \%$ & $80 \%$ & $75 \%$ & $60 \%$ \\
\hline
\end{tabular}

Chart 4. Cytotoxicity of 2ry, concentrations (1\%,0.5\% and $0.25 \%$ \& $0.125 \%)$ of CaPN on VERO cells in terms of cell viability percentage

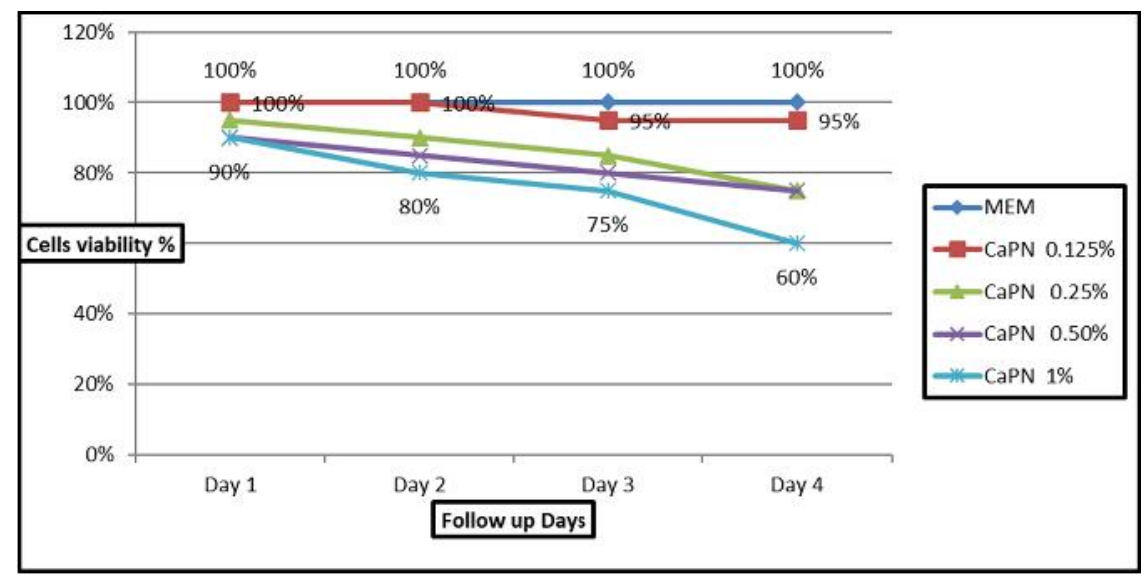

Table 5. Results of observations and follow up for CPE after PPRV inoculation in VERO cells for a period of 7 days in presence of different concentrations of CSN.

\begin{tabular}{ccccccc}
\hline $\begin{array}{c}\text { Day post } \\
\text { inoculation }\end{array}$ & Cell control & $1 \%$ & $0.5 \%$ & $0.25 \%$ & $0.125 \%$ & $\begin{array}{c}\text { Virus } \\
\text { control }\end{array}$ \\
\hline Day 1 & - & - & - & - & - & - \\
Day 2 & - & - & - & - & - & - \\
Day 3 & - & - & - & \pm & \pm & \pm \\
Day 4 & - & \pm & \pm & + & + & + \\
Day 5 & - & + & + & + & $2+$ & $2+$ \\
Day 6 & - & $2+$ & $2+$ & $2+$ & $3+$ & $4+$ \\
Day 7 & - & $3+$ & $3+$ & $3+$ & $4+$ & A.E.U. \\
\hline
\end{tabular}


Chart 5. Show the pattern of CPE eruption after PPRV inoculation to VERO cells with a simultaneous existence of CSN in different concentrations. V. control = Virus control (media type is MEM) C. control = Cell control (No virus inoculation)

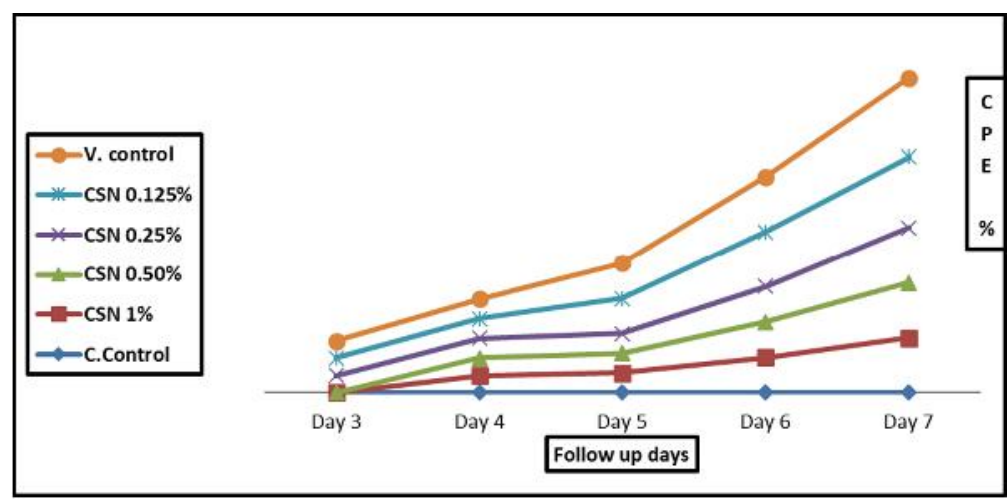

Table 6. Show observations and follow up for CPE after PPRV inoculation in VERO cells for a period of 7 days in presence of different concentrations of $\mathrm{CaPN}$.

\begin{tabular}{lllllll}
\hline $\begin{array}{l}\text { Day post } \\
\text { inoculation }\end{array}$ & $\begin{array}{l}\text { Cell } \\
\text { control }\end{array}$ & $1 \%$ & $0.5 \%$ & $0.25 \%$ & $0.125 \%$ & $\begin{array}{l}\text { Virus } \\
\text { control }\end{array}$ \\
\hline Day 1 & - & - & - & - & - & - \\
Day 2 & - & - & - & - & - & - \\
Day 3 & - & - & - & - & \pm & \pm \\
Day 4 & - & - & \pm & \pm & + & + \\
Day 5 & - & \pm & + & + & $2+$ & $2+$ \\
Day 6 & - & + & $2+$ & $2+$ & $4+$ & $4+$ \\
Day 7 & - & $2+$ & $3+$ & $3+$ & $4+$ & A.E.U. \\
\hline
\end{tabular}

Chart 6. Show the pattern of CPE eruption after PPRV inoculation to VERO cells with a simultaneous existence of $\mathrm{CaPN}$ in different concentrations V . control = Virus control (media type is MEM) $\mathrm{C}$. control = Cell control (No virus inoculation)

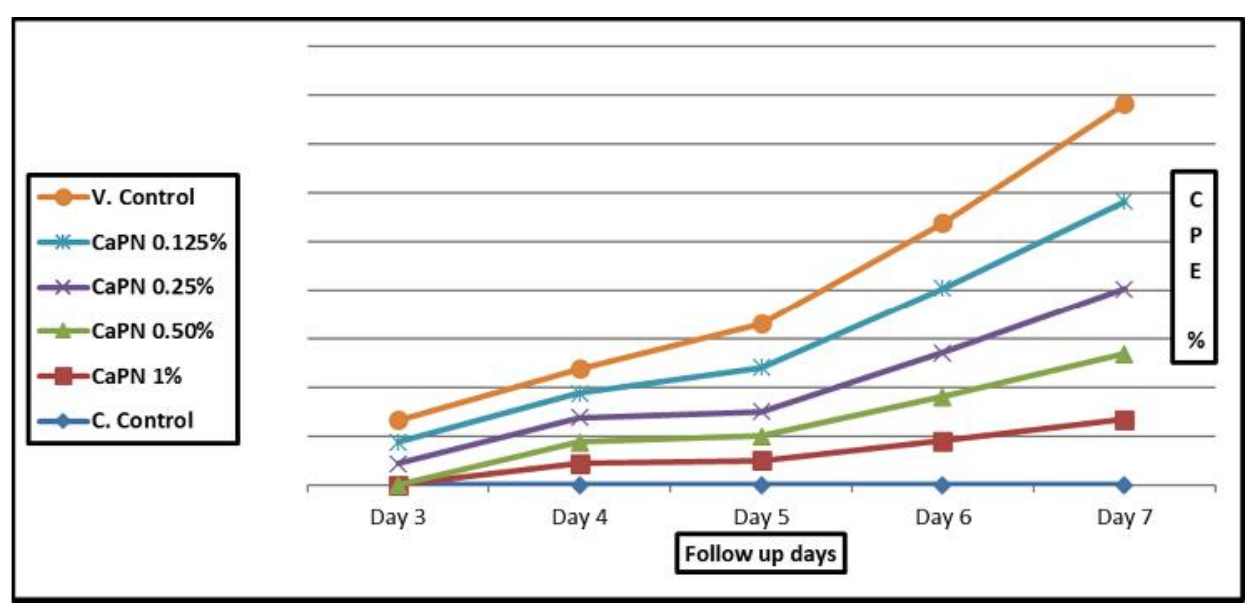


Table 7. The impact of CSN upon PPRV performance \& titer of PPRV expressed by $\log 10 \mathrm{TCID} 50 / \mathrm{m}$

\begin{tabular}{ccccccccccc}
\hline Type & \multicolumn{1}{c}{} & \multicolumn{9}{c}{ Days post PPRV inoculation } \\
Of & \multicolumn{2}{c}{ Day 3 } & \multicolumn{2}{c}{ Day 4 } & \multicolumn{2}{c}{ Day 5} & \multicolumn{2}{c}{ Day 6} & \multicolumn{2}{c}{ Day 7} \\
Media & CPE & Titer & CPE & Titer & CPE & Titer & CPE & Titer & CPE & Titer \\
\hline CSN 1\% & - & - & \pm & - & + & 0.5 & $2+$ & 1.8 & $3+$ & 3.2 \\
CSN 0.5\% & - & - & \pm & - & + & 0.7 & $2+$ & 2.5 & $3+$ & 3.3 \\
CSN 0.25\% & \pm & - & + & 0.7 & + & 0.8 & $2+$ & 2.6 & $3+$ & 3.4 \\
CSN 0.125\% & \pm & - & + & 0.9 & $2+$ & 2.1 & $3+$ & 5.8 & $4+$ & 6 \\
MEM & \pm & - & + & 1 & $2+$ & 2.2 & $4+$ & 6.1 & A.E.U & 2.5 \\
\hline
\end{tabular}

Table 8. The impact of CaPN upon PPRV performance \& titer of PPRV expressed by $\log 10 \mathrm{TCID} \mathrm{D}_{50} / \mathrm{m}$

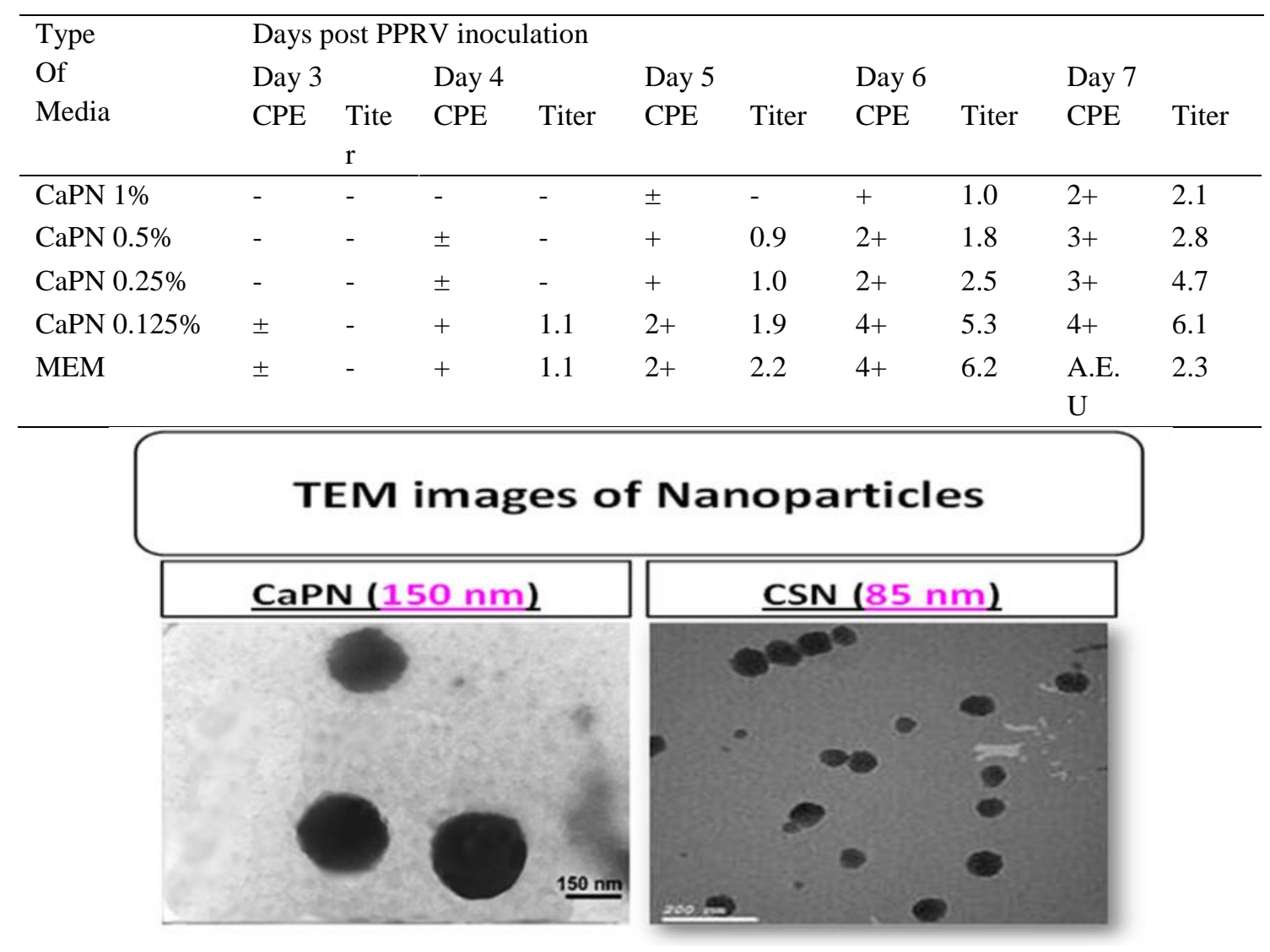

Figure 1: Mean particle Size of CSN (Right) and CaPN (Left) under TEM.

1\% Dilution (50\%)

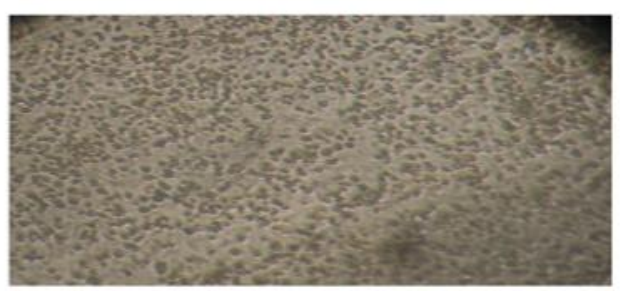

$0.125 \%$ dilution (95\%)

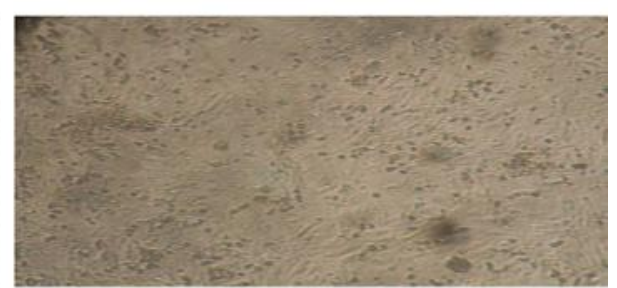

Figure 2: A comparison between the impact of CSN 1\% (left image) and CSN $0.125 \%$ (right image) concentrations upon VERO cells $\{4$ days post adding to MEM). (Images are taken using the inverted microscope, with a low power resolution). 

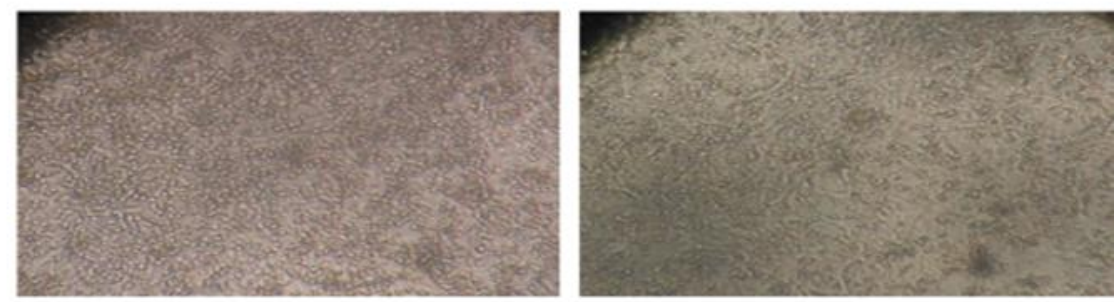

Figure 3: A comparison between CPE intensity for CSN 1\% (left image) AND CSN 0.125\% (right image) on VERO cells -7days post PPRV inoculation.
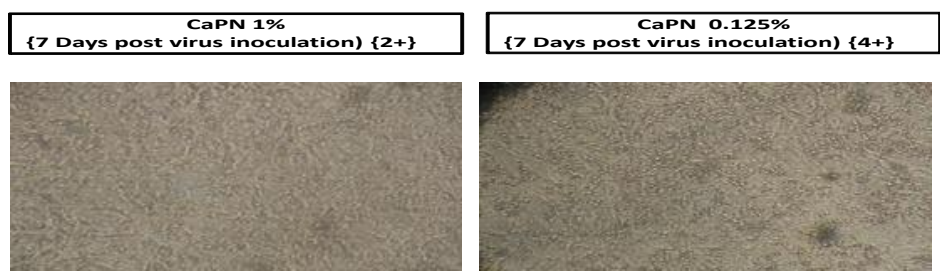

Figure 4: A comparison between CPE intensity for CaPN 1\% (left image) and CaPN 0.125\% (right image) on VERO cells -7days post PPRV inoculation.

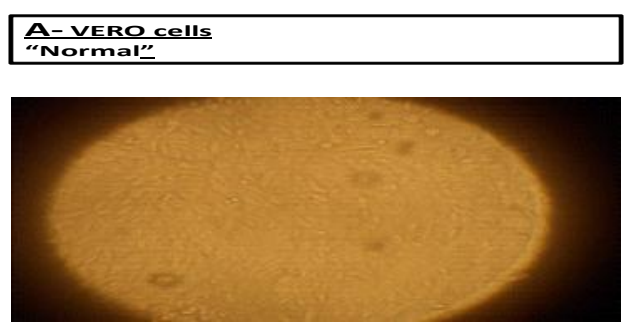

B-Vero cells,
\{ 7 days afterVirus inoculation (A.E.U.)\}

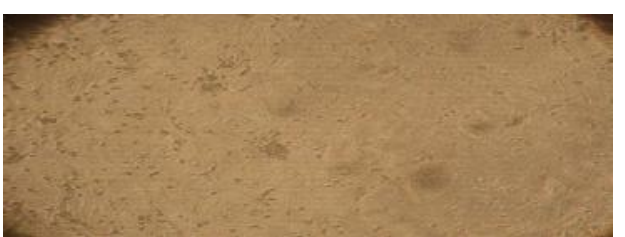

Figure 5: A comparison between Normal VERO cells (left image) employed in this study and VERO cells 7days post PPRV inoculation (Right image) where all sheet is eaten up (A.E.U.) and the used media was blank MEM.

\section{DISCUSSION}

Peste des petits ruminants appeared firstly in Egypt in January 1987, with a very high morbidities and mortalities (Ikram et al.1988).Vaccination remains the most cost effective biomedical approach to control infectious disease in livestock using either live attenuated or inactivated vaccines (Paillot et al., 2008).
Transmission electron microscopic measuring of NP used in this study indicated that CSN mean particle size was $85 \mathrm{~nm}$ while that of CaPN was $150 \mathrm{~nm}$, each of them still matching the size of VERO cells components and they were capable for effective uptake by the cells via pinocytosis and affect them (Treuel and Nienhaus, 2013).

For development of PPR vaccine preparation using nanoparticles, it was very essential to 
ensure that theses nanoparticles will work in a harmony with the principle bioelements (PPRV and VERO cells) that were used in vaccine preparation.

However, there was a consensus among the majority of scientists regarding the excellent characters of nanoparticles as $\mathrm{CSN}$ and $\mathrm{CaPN}$ relying upon their unique properties specially, their safety profile either for different types of cell lines used in vaccines preparation or the vaccinated live stocks that received vaccines supplied with these nanoparticles . But a need for more paying attention towards some crucial aspects regarding these nanoparticles should take place like concentration and particle sizes of these nanoparticles.

In this study, we found that although nanoparticles (CSN / $\mathrm{CaPN}$ ) are having a considerable tolerance towards VERO cells provided that an adjustment for the used concentrations that influence the particle size where high concentrations allow nanoparticles to agglomerate forming larger particles with a subsequent loss of their nanoparticles properties regarding cell tolerance as found in table (1) and (2) where CSN 1\% and CaPN 1\% after four days of the cytotoxicity experiment resulted in loss of cell viability by zero $\%$ and $20 \%$ respectively. On the other hand, after using lower concentration $(0.125 \%)$ from both of these NP and after spending the same period of four days VERO cells viability increased to more than $95 \%$. These results confirmed the need for use lower concentrations for low cytotoxicity upon VERO cells.

Study results went parallel to that obtained previously by (Siti et al.,2015, z.-x.Tang. et al., 2007, K.Haliza and A.H.Oya ., 2006) as well as (Q.Gan et al., 2005).Also, study results were supported by (Gunbeyaz et al., 2010) who concerned with the impact of particle size as well as the positive surface charges of CSN that acquired it the adhesiveness to cell membrane and hence, better uptake by cells.
On the contrary, results were -to some extentdisagreed with (Janvikul et al.,2007, Xhu et al.,2007 and Sayin et al.,2008).

Moreover, current study recorded no betterment impact for CSN/CaPN upon PPRV behavior as well as infectivity to VERO cells that recorded quantitatively by titration as in table (7) where CSN 1\% delayed the eruption of CPE to the fifth day however both of CSN $0.125 \%$ and virus control showed more rapid CPE eruption on the third day with a titer of 0.9 $\log 10 \mathrm{TCID}_{50} / \mathrm{ml}$ and $1 \log 10 \mathrm{TCID}_{50} / \mathrm{ml}$ respectively. Similar results were found in case of $\mathrm{CaPN}$ where $\mathrm{CaPN} 1 \%$ delayed $\mathrm{CPE}$ to the fourth day of titration while in CaPN $0.125 \%$ and virus control, CPE started on the third day with titers of $1.1 \log 10 \mathrm{TCID}_{50} / \mathrm{ml}$ for each of them. is contradicting with the obtained results by (Zhao et al., 2012) who stated that CSN induced an increment in the infectivity of Newcastle live attenuated vaccine virus. the difference may be owed to the difference in sizes between both of NDV(about 100-150 nm in diameter) and PPRV $(400-500 \mathrm{~nm}$ in diameter) (Munir et al 2013). This may be attributed by the smaller size of NDV comparing that of PPRV facilitated the uptake of virus that was adhered to NP by cultured cells.

\section{Conclusion}

Nanoparticles, are the new era for vaccine development, that offers a conditioned cellular tolerance and the concentration dependency was very vivid relying on a lot of factors as the method of preparation, concentrations, the concentration of $0.125 \%(\mathrm{~W} / \mathrm{V})$ in both of CSN and $\mathrm{CaPN}$ were the best to be used as a supplement to media used for PPRV propagation during the process of PPR vaccine production.

PPRV infectivity to VERO cells is not yet proved and need more investigations. 


\section{REFERENCES}

Abbas F., Ullah A., Ali M., Awan M.A., Tariq M.M., Khan F.A., Bajawa M.A., Ahmed Z., Rashid n., Wadood A. (2011): Production of tissue culture based peste des petits ruminants(PPR)vaccine.The journal of animal and plant sciences, 21(4):841:843.

Akagi T, Baba M, Akashi M. (2012): Biodegradlbe noanoparticles as vaccine adjuvant and delivery systems: regulation of immune responses by nanoparticlebased vaccine. In: Kunugi S, Yamaoka T,editors. Polymers in nanomedicine. Berlin Springer-Verlag Berlin; p.31-64 .

Arca HC, Gunbeyaz M, Senel S. (2001): Chitosan-based systems for the delivery of vaccine antigens. Expert Review of Vaccines:9; 8:937-53.

Arteam B, Richa J. (2017): Calcium phosphate nanoparticles as potent adjuvant and drug delivery agent. Curr Trends Biomedical Eng \& Biosci.;1(4):555585. DOI:10.19080/CTBEB.01.555555 .

Chen YY, Sun M, Ping Q (2014): A mini review of biodegradable calcium phosphate nanoparticles for gene delivery, Curr Pharm Biotechnol.;14 (10):918-925.

Cheng X, Kuhn L., (2007): Chemotherapy drug delivery from calcium phosphate nanoparticles. Int J. Nanomed.;2:667674.

Chua BY, AL Kobaisi M, Zeng WG, Mainwaring D, Jackson DC. (2012): Chitosan microparticles and nanoparticles as biocompatible delivery vehicles for peptide and protein-based immune contraceptive vaccines. Molecular Pharmaceutics; 9:81-90.

Couvreur P, Vauthier C. (2006): Nanotechnology: intelligent design to treat complex disease. Pharmaceutical Research; 23:1417-50.

Fernandez-Urrusuno, R.,Calvo, P., RemunanLopez, C., Vila-Jato, J. L. and Alonso, M.J. (1999): Enhancement of nasal absorption of insulin using chitosan nanoparticles. Pharm. Res. 16, 1576-1581.

Fischer, D., Li.Y., Ahlemeyer, B., Krieglstein, J., Kissel, T., (2003): In vitro cytotoxicity testing of polycations: influence of polymer structure on cell viability and hemolysis. Biomaterials 24, 1121-1131 .

Gibbs E J P., Taylor W P., Lawman M J P. and Bryant J. (1979): Classification of Peste des Petits Ruminant virus as the fourth member of the genus Morbilli virus. Inter Virology 11:268-274 .

Gunbeyaz, M.; Faraji, A.; Ozkul, A.; Parali, N. and Senel, S. (2010): Chitosan based delivery system for mucosal immunization against bovine herpes virus 1 (BHV-1). Eur J.Pharm. Sci. 41(34):531-45.

He Q, Mitchell A, Morcol T, Bell SJ. (2002): Calcium phosphate nanoparticles induce mucosal immunity and protection against herpes simplex virus type 2. Clinical and Diagnostic Laboratory Immunology; 9:1021-4 .

Haliza, K. and Oya, A. H., (2006): Development and characterization of chitosan nanoparticles for siRNAdelivery, Journal of controlled Release, vol. 115, pp. 216225.

He Q, Mitchell AR, Johnson SL, Wagner-Bartak C, Morcol T, Bell SJD. (2000): Calcium phosphate nanoparticle adjuvant. Clinical and Diagnostic Laboratory Immunology; 7:899-903.

Karim, A.I; A; El-danaf, N.A.; EL-Nakasly, S. and House, J. (1988): Isolation of a viral agent from Egyptian goats suspected to be 
PPR virus Infected, J. Egypt. Vet. Med. Ass., 48(3):429-435.

Janvikul, W., Uppanan, P., Thavornyutikarn, B., Prateepasen, R., Swasdison, S., (2007): Fibroblast interaction with carboxymethy-chitosan based hydrogels. J. Mater. Sci. Mater. Med. 18, 943-949.

John, K., N. D. J. Chandran, V. Ramaswamy, C. Balachandran and J. J Kirubaharan (2006): Adaptation of PPR vaccine virus in BHK21 monolayer culture Indian Vet. J. 7, 1143-1146.

Joyappa DH, Ashok Kumar C. Banumathi N, Reddy GR, Suryanarayana W. (2009): Calcium phosphate nanoparticle prepared with foot and mouth disease virus P13CD gene construct protects mice and guinea pigs against the challenge virus, Veterinary Microbiology;139:58-66.

Lefevre, P. C. and A, Diallo (1990): Peste des Petits Ruminants. Rev. Sci. Off. Int. Epiz, 9, 951-65.

Mody KT, Popat A, Mahony D, Cavallaro AS, Yu C, Mitter N. (2013): Mesoporous silica nanoparticles as antigen carriers and adjuvants for vaccine delivery. Nanoscale; 5:5167-79.

Moghimi SM, Hunter AC, Murray JC. (2005): Nanomedicine: current status and future prospects. The FASEB Journal; 19:31130.

Mohan, (2004): Characteristics of Peste des Petits Ruminants virus MVSc Thesis Tamil Nadu Veterinary and Animal Sciences University, Chennai India.

Munir, M., Zohari, S. and Berg, M. (2013): Current advances in molecular diagnosis and vaccines for peste des petits ruminants. In: Munir, M., Zohari, S. and Berg, M. (eds) Molecular Biology and Pathogenesis of Peste des Petits
Ruminants Virus. Springer, Berlin, Germany, pp.105-133.

Oberg AL, Kennedy RB, Li P, Ovysyannikova IG, Poland GA. (2011): Systems biology approaches to new vaccine development. Current Opinion in Immunology; 23:43643.

OIE (2004): Manual of Diagnostic tests and vaccines for Terrestrial Animals. 5th edn. Chapter 2.1.5 pp 153-162.

OIE (2010): Manual of standards for diagnostic tests and vaccines, 6th Ed. Sheep pox and Goat pox, 2.7.14.

Oyewumi MO, Kumar A, Cui Z. (2010): Nanomicroparticles as immune adjuvants; correlating particle sizes and the resultant immune response. Expert Review of Vaccines; 9:1095-107.

Paillot, R; Case, R; Ross, J.; Newton, R. and Nugent, J. (2008): Equine Herpes virus 1: Virus, Immunity and Vaccines. The open veterinary Science Journal, 2, 68-91.

Qi Gan, T. Wang, C. Cochrane, and P. McCarron, (2005): Modulation of surface charge, particle size and morphological properties of chitosan-TPP nanoparticles intended for gene delivery," Colloids and Surfaces B: Biointerfaces, vol. 44 , no. $2-3$, pp. $65-$ 73.

Qi, L., Xu, Z., Jiang, X., Hu, C. and Zou, X. (2004): Preparation and antibacterial activity of chitosan nanoparticles. Carbohydr. Res., 339: 2693-2700.

Qurashi, T.; Blair, H.S. and Alen, S.J.J. (1992): Studies on modified chitosan membranes. I. Preparation and characterization. J. Appl. Polym. Sci., 46: 255-261.

Rappuoli R, Mandl CW, Black S, De Gregorio E. (2011): Vaccines for the twenty-first century society. Nature Reviews Immunology,11:865-72. 
Reed, L.T. and Muench, H. (1938): A simple method of estimating $50 \%$ emd points. Am. J. Hyg., 27: 493. Rev. Vaccines 3 453-462

Saeed, M.I., Omar, A.R., Hussein M.Z., Elkhidir, M.I., and Sekawi, Z., (2015): Systemic antibody response tonano-size calcium phosphate biocompatible adjuvant adsorbed HEV-71 killed vaccine. Clin Exp Vaccine Res. 4(1):88-98.

Sayin, B.; Somavarapu, S.; Li, X.W.;Thanou, M.; Sesardic, D.; Alpar, H.O. and Senel, S. (2008): Mono-N-carboxymethyl chitosan (MCC) and N-trimethyl chitosan (TMC) nanoparticles for non-invasive vaccine delivery. Int.J.Pharm. 363(1-2):139-48.

Siti Sarah Omar Zaki, Mohd Nazmi Ibrahim, and Haliza Katas, (2015): Particle size affects concentration-dependent cytotoxicity of chitosan nanoparticles towards mouse hematopoietic stem cells. Journal ofnanotechnology; 919658:1-5.

Stieneker F, Kreuter J, Lower J. (1991): High antibody-titers in mice with polymethylmethacrylate nanoparticles as adjuvant for HIV vaccines. AIDS; 5:4315.

Temchura, V.V., Kozlova, D., Sokolova,V., Uberla, K. and Epple, M. (2014): Targeting and activation of antigen specific B-cells by calcium phosphate nanoparticles loaded with protein antigen. Biomaterials. 35(23):6098-105.

Treuel L. Jiang X, Nienhaus GU. (2013): New views on cellular uptake and trafficking of manufactured nanoparticles. Journal of the Royal Society Interface; 10:20120939.

Van Der Lubben, I.M., I.C. Verhoef, G. Borchard and H.E. Junginger, (2001): Chitosan for Mucosal Vaccination. Adv. Drug Del. Rev., 52: 139-144.
Wendorf J, Singh M, Chesko J, Kazzaz J, Soewanan E, Ugozzoli M, et al. (2006): A practical approach to the use of nanoparticles for vaccine delivery. Journal of Pharmaceutical Science; 95:2738-50.

Xhu, Bol., Qie, Yq., Wang, J.I., Zhang, Y., Wang, Q.Z., Xu, Y. and Wang, Hh. (2007): Chitosan microspheres enhance the immunogenicity of an Ag85B - based fusion protein containing multiple T-cell epitopes of mycobacterium tuberculosis. Eur. J. Pharm. Biopharm., 6 (3): 318-26.

Xu,Y., and Du, Y.(2003): Effect of molecular structure of chitosan on protein delivery properties of chitosan nanoparticles. Int. J. Pharm. 250, 215-226.

Z.-X. Tang, J.-Q. Qian, and L.-E. Shi, (2007): Preparation of chitosan nanoparticles as carrier for immobilized enzyme," Applied Biochemistry and Biotechnology, vol. 136, no. 1, pp. 77-96.

Zhao, K., Chen, G., Shi, X.M., Gao, T.T., Li, W., Zhao, Y., Zhang, F.Q., Wa, J., Cui, X. and Wang, Y.F. (2012): Preparation and efficacy of a live Newcastle disease virus vaccine encapsulated in chitosan nanoparticles. Plos One, 7 (12): 1-11.

Zhao, L.; Seth, A.; Wibowo, N.; Zahao, C.; Mitter, N.; Yu, C. and Middelberg, A. (2014) Nanoparticles vaccines, Elsevier; $32: 327-337$ 